\title{
Vivências da vida conjugal: posicionamento das mulheres*
}

\author{
Marital life experiences: women's positioning
}

Vivencias de violencia conyugal: toma de posición por parte de las mujeres

\author{
Cláudia Maria Ramos Medeiros Souto', Violante Augusta Batista Bragall \\ 'Universidade Federal da Paraíba. Departamento de Enfermagem de Saúde Pública. \\ Grupo de Estudos e Pesquisas Mulher, Saúde e Gênero. João Pessoa, PB \\ "Universidade Federal do Ceará. Departamento de Enfermagem. Fortaleza, CE
}

Submissão: $05 / 04 / 2009$

Aprovação: $31 / 08 / 2009$

\section{RESUMO}

Estudo de abordagem Qualitativa, realizado com onze mulheres em situação de violência conjugal. Os dados empíricos foram produzidos mediante oficinas, buscando-se a compreensão das vivências de violência nos discursos das mulheres. Para a composição das categorias analíticas utilizamos a técnica de análise temática de conteúdo. Procedemos a análise foi feita com base nos constructos da categoria gênero presentes ao cotidiano dessas mulheres. Os resultados mostraram que a violência conjugal representa para as mulheres o medo e o aprisionamento e Que, na conjugalidade, a mulher está mais susceptível às relações desiguais de poder, com domínio masculino e legitimação da violência. Nas suas falas ficaram evidentes comportamentos e atributos Que sustentam a condição feminina de sujeição ao marido e à violência.

Descritores: Enfermagem; Gênero e saúde; Saúde da mulher; Violência contra a mulher.

\section{ABSTRACT}

A study of Qualitative approach, carried out with eleven women in a marital violence situation. Empirical data were produced from workshops, focusing on the understanding of violence experience through the women's speech. In order to compose analytic categories we used the technique of content's thematic analysis. The analysis was done based on constructs of gender categories present in the daily life of those women. Results showed that marital violence represents to the women fear and imprisonment and that since within a marital status the woman is more susceptible to undergo unfair relations of power with male dominance and legitimation of violence. In the women's speech became evident behaviors and attributes that support the feminine condition of subjection to the spouse and to violence. Descriptors: Nursing; Gender and health; Women's health; Violence against women.

\section{RESUMEN}

Se trata de un estudio de carácter cualitativo, realizado con once mujeres en situación de violencia conyugal. Los datos empíricos fueron obtenidos en talleres. Se buscó la comprensión de la vivencia de la violencia a través de los discursos d las mujeres. Para formar las categorías analíticas utilizamos la técnica de análisis temático de contenido. El análisis se fundamentó en los constructos de la categoría género presentes en la vida cotidiana de esas mujeres. Los resultados mostraron que la violencia conyugal representa para las mujeres: miedo y aprisionamiento, y Que en la conyugalidad, la mujer está más susceptible a relaciones desiguales de poder, con dominio masculino y legitimación de la violencia. En las hablas de las mujeres, se evidenciaron comportamientos y atributos Que sustentan la condición femenina de sujeción al cónyugue y a la violencia.

Descriptores: Enfermería; Genero y salud; Salud de la mujer; Violencia contra la mujer.

*Artigo extraído da pesquisa de doutorado intitulada "Violência conjugal sob o olhar de gênero" realizada através do Programa de Pós-Graduação em Enfermagem da Universidade Federal do Ceará, concluída em 2008.

Correspondência: Cláudia Maria Ramos Medeiros Souto. Av. Olinda, no 385, Apto. 202, Tambaú, CEP 58.039-120, João Pessoa, PB, 


\section{INTRODUÇÃO}

Com uma prática docente voltada à saúde da mulher, compreendemos Que a saúde possui interfaces com as relações de gênero, e Que estas podem produzir fenômenos como a violência conjugal, com potenciais danos ao seu bem estar, causando-lhes até a morte.

Sobre a violência conjugal praticada contra a mulher se insere um conceito mais amplo: o da violência contra a mulher, definido em 1993, na Assembléia Geral das Nações Unidas: QualQuer ato de violência de gênero Que resulte ou possa resultar em dano físico, sexual ou psicológico ou sofrimento para a mulher, inclusive ameaças de tais atos, coerção ou privação arbitrária da liberdade, Quer isso ocorra em público ou na vida privada ${ }^{(1)}$.

Gênero pode ser definido como um conjunto de características sociais, culturais, políticas, psicológicas, jurídicas e econômicas atribuídas às pessoas, de forma diferenciada, de acordo com o sexo. A violência conjugal é uma violência de gênero, porQuanto é produzida nas relações sociais e a sociedade atribui à mulher e ao homem papéis e direitos desiguais. Em conseqüência disso, a violência passa a ser considerada, muitas vezes, um ato normal ou natural, permanecendo invisível e ineuestionável, convergindo para uma subvalorização do fenômeno e de seus efeitos.

Buscando a ampliação de olhares para a violência conjugal este estudo teve por objetivo investigar fatores Que contribuem para a permanência ou para o rompimento de relações conjugais violentas e os significados atribuídos a essas vivências.

\section{METODOLOGIA}

\section{Caracterização do estudo}

Este estudo está contemplado dentro de uma abordagem Qualitativa, pois se trata de uma investigação em Que subjaz uma ideologia, e veicula interesses e visões de mundo historicamente construídas, submete-se e resiste aos limites dados pelos esquemas de dominação vigentes ${ }^{(2)}$. Neste caso, a ideologia de gênero.

\section{Cenários de investigação}

Os cenários para o desenvolvimento do estudo foram uma Organização Não-Governamental e o Pronto Atendimento Médico (PAM da Primavera), ambos situados no Município de João Pessoa (PB).

\section{Universo empírico e aspectos éticos}

Onze mulheres fizeram parte da amostra mediante a assinatura do Termo de Consentimento Livre e Esclarecido ${ }^{(3)}$. A pesquisa foi aprovada pelo Comitê de Ética e Pesquisa, do Centro de Ciências da Saúde, da Universidade Federal da Paraíba (UFPB), protocolado sob o número 766/06, em 25 de outubro de 2006.

\section{Produção do material empírico}

A oficina como um dispositivo de construção coletiva do conhecimento, de partilha de experiências, como espaço de acolhimento e de escuta e como modalidade metodológica foi utilizada para produção dos $\operatorname{dados}^{(4)}$.

\section{Análise do material empírico}

A técnica de análise temática de conteúdo foi utilizada em três etapas básicas: pré-análise, descrição analítica e interpretação inferencial $^{(5)}$ para a categorização dos dados. Procedemos a análise dos dados com base no referencial de gênero entendido, neste estudo, como um elemento constitutivo das relações sociais, baseado nas diferenças percebidas entre os sexos, e o gênero é uma forma primeira de significar relações de $\operatorname{poder}^{(6)}$.

\section{RESULTADOS E DISCUSSÃO}

\section{O perfil das mulheres e da violência conjugal}

As idades das mulheres variaram entre os vinte e um e os Quarenta e nove anos. O baixo nível de instrução e de renda predominou no grupo. Embora o fenômeno da violência praticada contra as mulheres acometa muitas no mundo inteiro, atingindo todas as idades, graus de instrução, religião, classe social, raça/ etnia e orientação sexual ${ }^{(7)}$, fatores socioeconômicos e culturais a Que elas e as outras pessoas de sua convivência estão submetidas (como por exemplo, a aglomeração espacial ou a falta de esperança) poderiam expô-las a uma maior vulnerabilidade social. Além disso, homens Que vivem em condições de pobreza podem tornar-se tensos e frustrados ou sentir Que fracassaram ao descumprir o papel culturalmente definido para ele, Qual seja, o de responsável pelo sustento a família(l).

O tempo de exposição à violência foi o de três anos ou mais. Lançamos um olhar para a construção das identidades de gênero, ao analisar as respostas das mulheres, no Que tange ao tempo de exposição em situação de violência e sobre violência em suas famílias de origem. Entendemos Que os comportamentos delas estão condicionados aos atributos construídos, existindo uma estreita relação entre a condição feminina sustentada - a partir da condição de subordinação da mulher - e o Que se reflete principalmente no lugar Que ela ocupa no casamento e na família.

A feminilidade Que é o constructo social, é vista como complemento da masculinidade. Isso menospreza capacidade da mulher para autodeterminar-se sexual e socialmente, tornando-a mais vulnerável ao abuso físico e emocional masculino. É com base nesse pressuposto Que, desde a infância, as mulheres são socializadas na perspectiva de alcançar a sua realização (complementação) no casamento idealizado, mediante o Qual os papéis de mãe, esposa e mulher seriam plenamente sucedidos.

Envolvidas afetivamente e imbuídas nesse processo de naturalização, as mulheres vivenciam episódios de violência praticados pelo esposo contra elas como resultado de uma necessidade constante de confirmação das relações de poder estabelecidas. Essas situações vivenciadas por longos períodos fragilizam-nas e as tornam mais vulneráveis, pondo-as em menor condições de enfrentamento.

Ao falarem sobre os motivos Que as levavam a permanecer junto aos agressores, a maior parte delas respondeu Que se achavam incapazes de negociar mudanças por parte do esposo e de enfrentar a situação, pois sentiam-se desvalorizadas, com uma auto-imagem negativa e sentimentos de desamparo, inferioridade, insegurança.

Um estudo realizado em Fortaleza identificou resultados sugestivos de algum grau de depressão na maioria das participantes de um grupo de cem mulheres Que prestaram Queixa na Delegacia da Mulher do Cearán ${ }^{(8)}$. Também apresentavam sintomas somáticos, ansiedade, insônia e distúrbios sociais. Alegaram incerteza acerca 
de Querer se separar, insegurança na capacidade de viver sem o outro cônjuge, medo de dificuldades para prover o sustento econômico. Essas respostas refletem o Que é esperado das mulheres, com relação ao cumprimento dos papéis sociais no casamento e na família. Responsabilizadas por se casar e ter filhos e manter o lar, sentem-se culpadas, inseguras e temerosas.

Outros sentidos relatados, como esperança na mudança de atitude do outro, tendência para justificar o comportamento violento do outro cônjuge e tendência para valorizar o papel de bom pai, mostram como a mulher assume uma atitude de aceitação e se submete ao Que é ditado pelas normas sociais, cumprindo os seus papéis sociais. Não raras vezes, se culpa pelo comportamento violento e agressivo do esposo, em detrimento da preservação desses "status sociais" ocupados por ela. Isso é observado em todos os espaços sociais, mas, sobretudo, essa posição é legitimada dentro da família, é legitimada essa posição acerca do marido, do pai, dos irmãos e dos filhos, em especial os do sexo masculino. No entanto, a violência conjugal não é experimentada de modo unânime, ou seja, as respostas das mulheres Que a vivenciam não têm um caráter universalizante, mas socialmente estruturado no modo como esses elementos - gênero associado com os outros elementos, como idade, condições familiares, sociais, econômicas e culturais - se associam ou não na vida delas ${ }^{(9)}$.

\section{Significação das vivências na violência conjugal}

Ao buscarem um significado para a vivência da violência conjugal, as mulheres expressaram sentimentos de medo e aprisionamento. Essa linguagem transparecida nas falas, nos gestos, na postura, nas crenças e valores revela o mundo da vida delas, como se sentiam, percebiam e pensavam, com relação às suas experiências de violência, pois na linguagem torna-se visível o Que é real acima da consciência de cada um ${ }^{(10)}$. Portanto, é a linguagem Que proporciona a experiência desses mundos revelados nos depoimentos seguintes.

\section{Medo}

Ao atribuírem significados aos seus relacionamentos violentos, as mulheres expressaram medo, o Que vem destacado nos depoimentos apresentados abaixo:

Muitas vezes tremia, sem saber por Que sentia aquele tremor, mas era medo mesmo. Lembrei muito daquele tremor que eu senti, e assim foram muitos, muitos anos de violência Que eu passei (choro). (Rosa, 38 anos, 18 anos em situação de violência).

Eu tinha medo porque ele batia em mim também. Quebrou meu braço, ele fazia o que Queria. Eu tinha medo (Lua, 49 anos, 30 anos em situação de violência).

O medo é o sentimento de viva inquietação ante a noção de perigo real ou imaginário, de ameaça, pavor e temor ${ }^{(1)}$. Interpretamo-lo nas falas como manifestações legítimas da sensação de ameaça sentida, mediante o perigo da agressão. Esta provoca dor, sofrimento, humilhação, vergonha, tristeza, tudo isso vivenciado no cotidiano dessas mulheres. O medo aparece como um modo de intimidá-las, de oprimi-las, e controlá-las. Parece contribuir para silenciarem o problema da violência conjugal. A relação violenta é também mantida, invisibilizada e silenciada por esses sentimentos perante os estereótipos cultuais e atitudes sociais negativas, no Que tange à violência"(12). Com o passar do tempo, o medo e a vergonha podem levar ao isolamento, impedindo a mulher de se expor a uma situação de risco, de buscar apoio, limitando possibilidades de ajuda e, consequentemente, tornando-a mais dependente do agressor. $\mathrm{O}$ medo da violência também alimenta o da repressão da liberdade ${ }^{(13)}$.

Além do constrangimento permanente, limita o seu acesso da mulher às atividades e recursos básicos. Mesmo Que essa violência seja denunciada, o temor gera sentimentos ambivalentes em relação ao agressor: ora ela o repudia, ora ela tem uma tendência para aceitar a situação ${ }^{(14)}$, ou tende a minimizá-la devido a esses fatores, falta de informação e de consciência do Que a constitui realmente e ainda pelo desejo de crer Que o parceiro não é tão mau ${ }^{(15)}$.

A par do estado de ameaça, de aprisionamento, de culpa, o medo modifica a auto-estima das mulheres. Por não conseguirem reagir, recorrem a mecanismos de defesa, como estratégias de adaptação e de sobrevivência. Acaba sendo um instrumento de persuasão e de controle do agressor, constitutivo das relações de gênero Que oprimem e impõem subordinação ${ }^{(16)}$. É um fator Que pode estar associado aos processos de sujeição das mulheres, contribuindo para Que elas permaneçam por um tempo mais longo em situação de violência, expondo-se mais aos riscos e às ameaças à saúde e à vida.

\section{Aprisionamento}

O significado da violência conjugal foi representado, também, por aprisionamento, em conseQüência de sua vivência em cárcere privado. Em seus depoimentos, elas expressam sentimento de perda de liberdade:

Como se eu vivesse sempre ali, presa, trancada, eu não via a cor do mundo, nem sabia me expressar às pessoas (Dani, 44 anos, casada, auxiliar de enfermagem, servidora pública, três filhos, 15 anos em situação de violência, rompeu com o agressor).

Isso aqui eu fiz foi assim: eu vivia assim entre Quatro paredes, sem ver o céu, sem ver nada. Aí pra mim isso aqui são trevas, é escuridão. (Eleni, 22 anos, 4 filhos, estudante, 6 anos em situação de violência, rompeu a relação).

As mulheres denunciaram uma relação fadada na idéia de perda de liberdade, no encarceramento, na dominação, na apropriação sentenciada pelo outro. O aprisionamento, tão profundamente enraizado, encobre em si mesmo sentimentos de negação, de submissão, e de ocultamento, Que reflete uma auto-estima fragilizada $^{(16)}$.

O medo de ficar sozinha pode ser um coadjuvante ao aprisionamento da mulher. A condição para ela mulher, mediante os papéis estereotipados de gênero, conservam a subordinação feminina e contribuem para a prática do abuso ${ }^{(16)}$. Ela define-se em função de uma relação e não se imagina sozinha ou, muitas vezes, mantém-se durante longo tempo numa relação abusiva planejando o momento oportuno para abandonar o marido, sem esquecer as pressões sociais, a vergonha, o medo de represálias e ausência de redes de apoio $^{(17)}$. 
Outra face da violência se revela no medo de perder os filhos como conseqüência do rompimento da relação. A mulher mostrase afetada e fragilizada pela ausência deles, sobretudo Quando se encontram na guarda do outro cônjuge nos casos, em Que há dependência financeira da mulher, o que torna o rompimento ainda mais complicado e difícil.

Assumir uma atitude de rejeição e de enfrentamento da violência exige dela não só coragem, mas a renúncia a um projeto de vida, fadado na família e na conjugalidade, o modelo idealizado para a mulher. Representa também a necessidade de busca de garantia de sobrevivência, de apoio institucional (policial e jurídico) e, não raras vezes, de proteção da vida. O desejo de ter e de manter uma família contribuem para a posição de submissão.

Os fatores discutidos - aprisionamento, isolamento social, submissão, a idealização dos papéis femininos - contribuem tanto para Que o espaço doméstico seja um cenário favorável para o exercício da violência, Quanto para a sua invisibilidade e, consequentemente, para sua impunidade.

\section{CONSIDERAÇÕES FINAIS}

Fui instigada a peseuisar as vivências de esposas em situação de violência conjugal para descobrir seus significados para as mulheres, compreender suas peculiaridades e as motivações ou barreiras Que as encaminham para o enfrentamento ou para a aceitação da condição vivenciada. Entendemos Que o gênero permeia as relações entre mulheres e homens - as relações conjugais - e resulta em desigualdades de posições, de direitos, de autonomia, de autoridade, de deveres, de acessos, de bens, entre outros.

Os resultados mostraram Que a violência conjugal representa para as mulheres medo e aprisionamento, decorrentes da intimidação, da ameaça de agressão e do controle manipulado pelo agressor. Tudo isso pode reverter em isolamento social e no afastamento de pessoas Que têm para elas bom significado afetivo.

Consequentemente, limita as redes de apoio, diminuindo possibilidades de ajuda e de enfrentamento, mantendo-a cada vez mais próxima do agressor, mais fragilizada e mais dependente dele. Os sentimentos de medo e de aprisionamento, com o tempo, também geraram o silêncio, contribuindo para um maior tempo de exposição das mulheres à situação de violência.

O estudo mostrou Que, na conjugalidade, a mulher está mais susceptível às relações desiguais de poder, com domínio masculino e legitimação da violência, apesar das mudanças ocorridas na sociedade em favor dela. Nas falas das entrevistadas ficaram evidentes comportamentos e atributos Que sustentam a condição feminina de sujeição ao outro cônjuge e à violência. Para algumas mulheres, o casamento se configura como o mais importante lugar Que elas poderiam ocupar, mesmo em condições violentas, pelos papéis sociais internalizados. Mas é também na relação conjugal Que as desigualdades de gênero são mais presentes, sobretudo nos modelos mais tradicionais de família e casamento. Nestes ainda se conserva a posição de provedor econômico no homem e a de provedora sexual na mulher. Por outro lado, os elementos constitutivos da masculinidade confirmaram as relações de poder estabelecidas dos homens sobre as mulheres.

Nesse contexto, lembramo-nos de nossa condição de mulher, enfermeira e pesquisadora. É pertinente anunciarmos Quanto nossas angústias foram mobilizadas em todos os momentos desta pesQuisa, ante relatos de crueldade, de perversidade e de sofrimento. Questionamos as nossas impotências, limites, valores, crenças, preconceitos e motivações, tudo em relação aos interesses em estudar a violência conjugal.

Em todos os momentos, este trabalho mobilizou nossa condição feminina e nos conduziu à reflexão sobre nossos papéis e práticas exercidas no dia-a-dia e no reconhecimento de Que a violência conjugal é um fenômeno presente no cotidiano, de várias mulheres, de forma cíclica e, consequentemente, sucessiva, porém sutil pela sua naturalização, pelas suas peculiaridades - a intimidade com o agressor, a relação de afeto, os valores culturais atribuídos. Este mal deve ser combatido, em vista de suas conseqüências deletérias.

\section{REFERÊNCIAS}

1. Organização Mundial da Saúde. Temas mundiais de saúde. Como acabar com a violência contra as mulheres. Population Reports 1999; 28(4): 43-5.

2. Minayo MCS. Pesquisa, método e criatividade. $16^{\text {a }}$ ed. Petrópolis: Vozes; 1994.

3. Ministério da Saúde (BR). Conselho Nacional de Saúde. Comissão Nacional de Ética em PesQuisa - CONEP. Resolução no 196/96. Dispõe sobre pesquisa envolvendo seres humanos. Brasília: Ministério da Saúde; 1996.

4. Portella AP, Gouveia T. Feminismo, educação e gênero. In: Portella AP, Gouveia T. Idéias e dinâmicas para trabalhar com gênero. Recife: Editora do Nordeste; 1999.

5. Bardin L. Análise de conteúdo. Lisboa: Edições 70; 1977.

6. Scott I. Gênero: uma categoria útil de análise histórica. Rev Educ Realidade 1995; 2( 20): 7 1-99.

7. Ministério da Saúde. Conselho Nacional de Saúde. A violência contra a mulher é também uma Questão de saúde pública [on line] 1997. [citado em 23 mai 2008]. Disponível em: http://portal.saude.gov.br/ portal/saude/cidadao/area.cfm?id_area $=1126$.

8. Aldeodato VG, Carvalho RR, Siqueira VR, Souza FGM. Qualidade de vida e depressão em mulheres vítimas de seus parceiros. Rev Saúde Pública 2005; 39(I); 108-13.

9. Dantas-Berger, SM, Giffin K. A violência nas relações de conjugalidade: invisibilidade e banalização da violência conjugal? Cad Saúde Pública 2005; 2 I (2): 417-25.

10. Gadamer HG. Verdade e método I: traços fundamentais de uma hermenêutica filosófica. 7ª ed. Petrópolis: Vozes; 2005.

II. Ferreira ABH. Miniaurélio: o minidicionário da língua portuguesa. Curitiba: Positivo; 2004.

12. Guedes RN, Silva ATMC, Coelho, EAC, Silva CC, Freitas WMF. A violência conjugal sob o olhar de gênero: dominação e possibilidade de desconstrução do modelo idealizado hegemonicamente de casamento. Online Braz I Nurs 2007; 6(3).

13. Celmer E. Violência contra a Mulher, produção legislativa e discurso punitivo - um estudo sobre a Lei Maria da Penha (I I.340/06) Rio Grande; 2007. [citado em I abr 2008]. Disponível em: http:// www.forumseguranca.org.br/artigos/violencia-de-genero-producaolegistativa-e-discurso-punitivo 
Souto CMRM, Braga VAB.

14. Pazo C. Reflexões acerca de um Disque-Mulher. Centro de Estudos da Mulher Urbana e Rural. Nova Friburgo; 2008. [citado em 5 mai 2008]. Disponível em: http://www.sermulher.org.br/site index.php?a=artigos\&ncat $=17 \&$ nid $=36$

15. Monteiro CFS, Souza IE. Vivência da violência conjugal: fatos do cotidiano. Texto Contexto Enferm 2007; I6(1): 26-31.

16. Narvaz MG, Koller SH. Mulheres vítimas de violência doméstica. Psicol 2006; 37(1): 7-13.

17. Matos M. Violência conjugal. In: Gonçalves RA, Machado C. Violência e vítimas de crime. Coimbra: Quarteto; 2002. 